
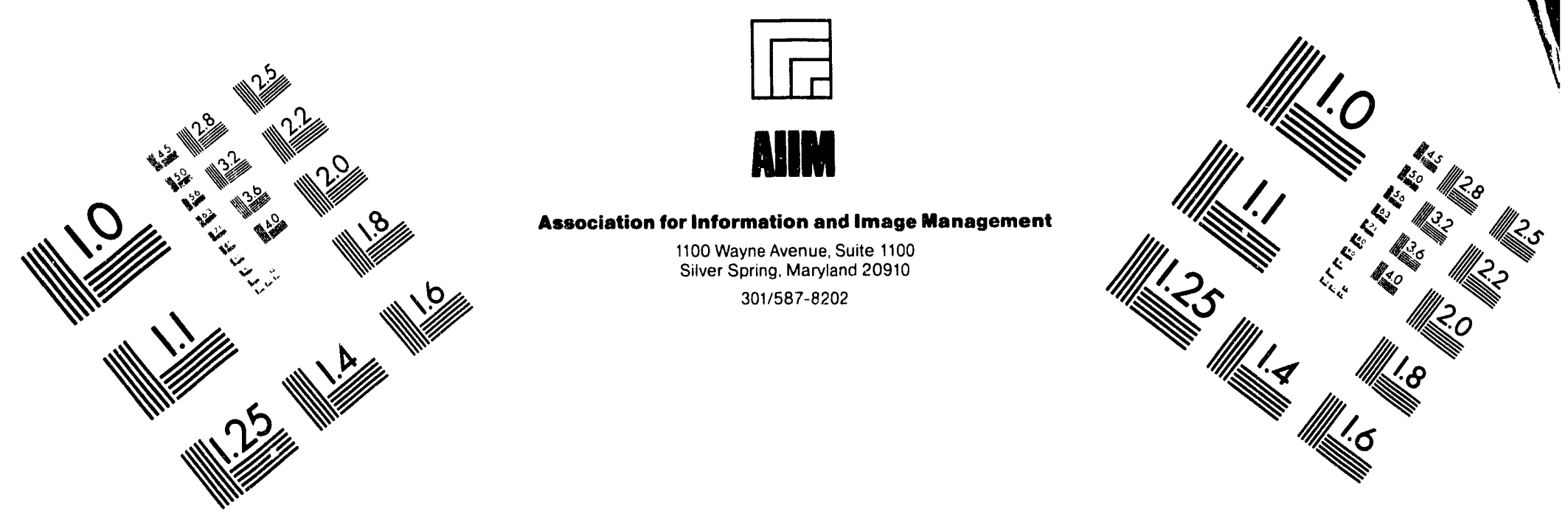

\title{
Centimeter
}

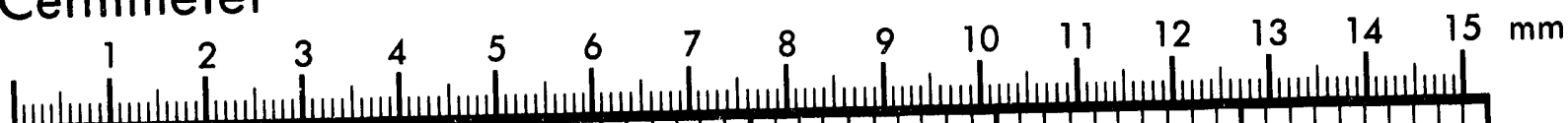
| Inches
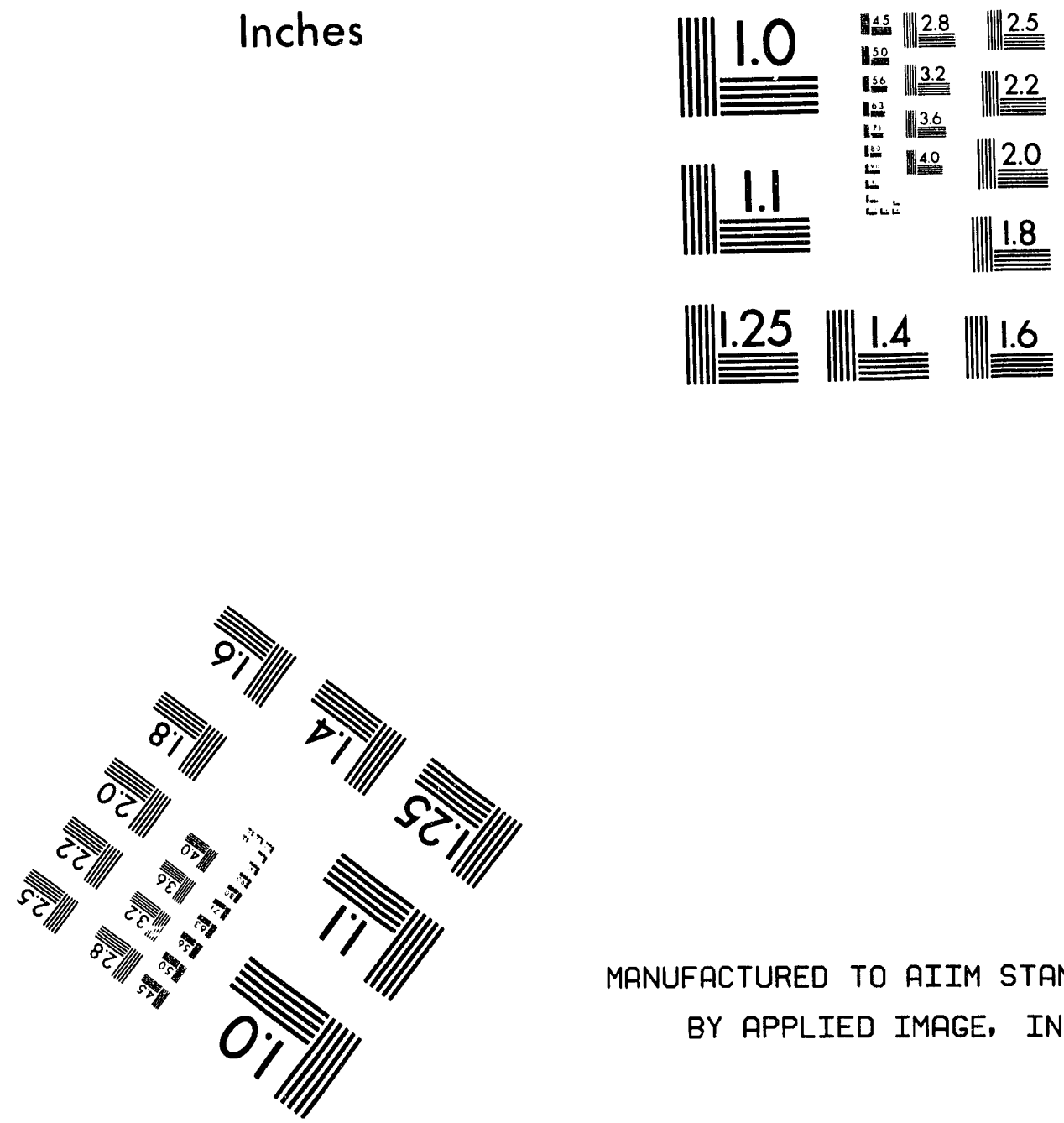

MANUFACTURED TO AIIM STANDARDS

BY APPLIED IMAGE, INC.

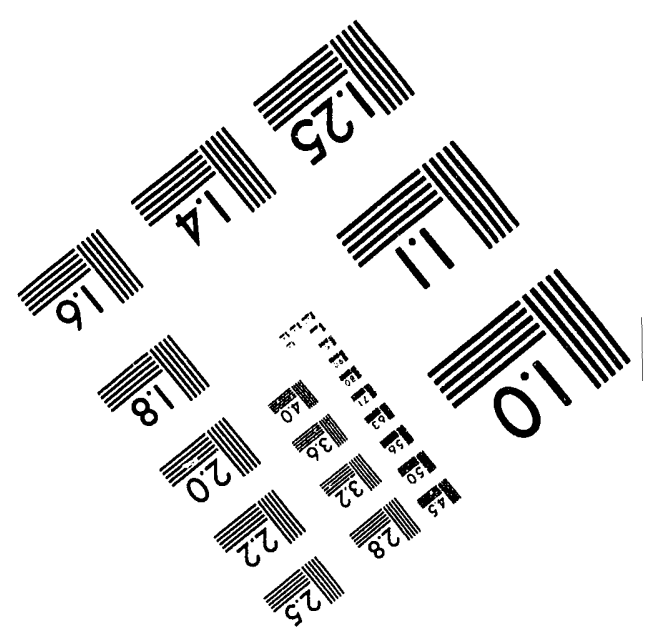



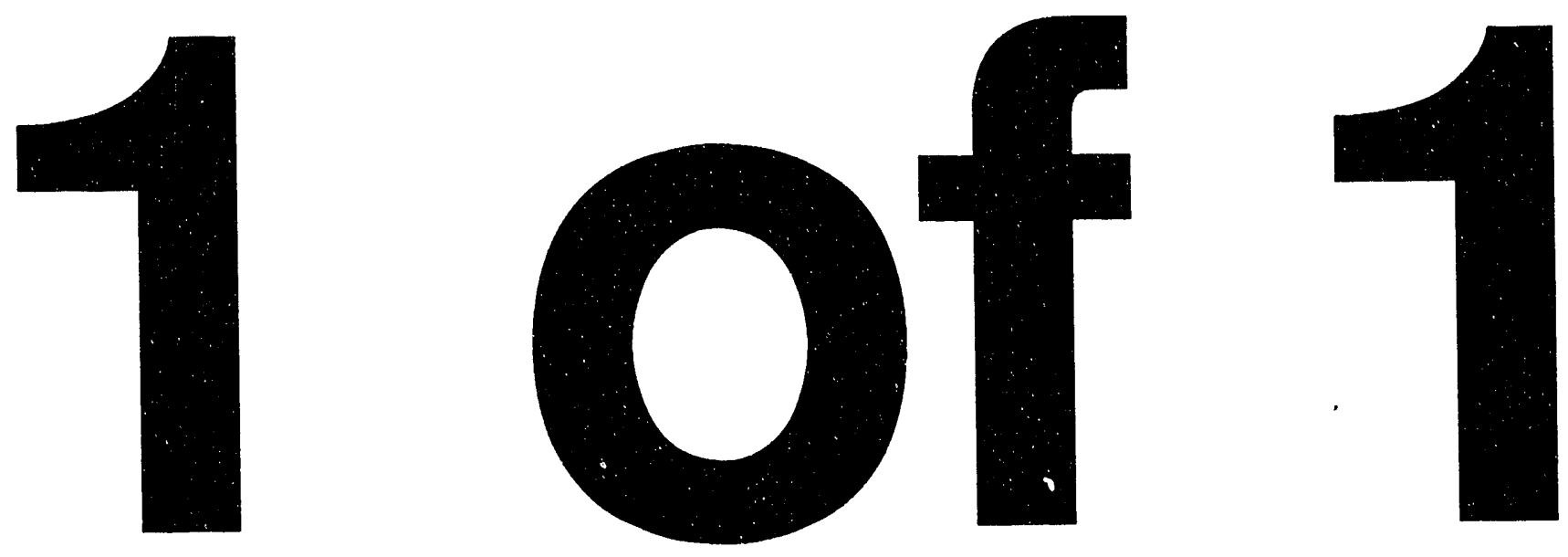


\title{
Conf-9309175 - -
}

\section{MICROSTRUCTURALLY BASED THERMOMECHANICAL FATIGUE LIFETIME MODEL OF SOLDER JOINTS FOR ELECTRONIC APPLICATIONS}

\author{
D. R. Frear \\ Center for Solder Science and Technology \\ Sandia National Laboratories \\ Albuquerque, NM \\ M. M. Rashid and S. N. Burchett \\ Engineering Sciences and Materials Modeling Department \\ Sandia National Laboratories \\ Albuquerque, NM
}

\section{ABSTRACT}

We present a new methodology for predicting the fatigue life of solder joints for electronics applications. This approach involves the integration of experimental and computational techniques. The first stage involves correlating the manufacturing and processing parameters with the starting microstructure of the solder joint. The second stage involves a series of experiments that characterize the evolution of the microstructure during thermal cycling. The third stage consists of a computer modeling and simulation effort that utilizes the starting microstructure and experimental data to produce a reliability prediction of the solder joint. This approach is an improvement over current methodologies because it incorporates the microstructure and properties of the solder directly into the model and allows these properties to evolve as the microstructure changes during fatigue.

\section{INTRODUCTION}

Solder joints were initially designed to be simple electrical interconnections between mechanically interlocked components in electronic packages. As technology advanced, electrical component size decreased, and the number of input/output terminations increased. To accommodate these changes, the numbers of solder joints per package have increased, while joint dimensions have decreased. The mechanically interlocked components were replaced by plated-through-hole technology which is now being pushed aside by surface mount technology (SMT). With each technological advance, the solder joint was expected to be not only an electrical conductor but also an increasingly important structural member with a smaller and smaller feature size. The benefits of shrinking solder joint dimensions are numerous (e.g., increased speed, greater packing density, etc.) but the number of reliability concerns increase exponentially. The critical nature of these small electrical-mechanical interconnections calls to question: Just how reliable are the solder joints in a modern electronic package?

A key issue in the long term reliability of solder joints is joint failure during thermal cycling. The individual components that are soldered together in an electronic package typically have differing thermal expansion coefficients. For example, SMT a ceramic chip carrier with a coefficient of thermal expansion of $6 \times 10^{-6} /{ }^{\circ} \mathrm{C}$ is soldered to a polyamide circuit board with a thermal expansion of $15 \times 10^{-6} /{ }^{\circ} \mathrm{C}$. When the soldered assembly un- 
dergoes a thermal cycle, strain is imparted to the solder joint. Nominally, the imposed strains can range from less than $1 \%$ up to $20 \%$. These thermally induced cyclic strains result in thermomechanical fatigue and often failure of the solder joints.

In the past, strain was minimized in solder joints by mechanically bonded leads, or leads designed with "stress loops" to isolate deformation from the solder. Strain to the solder joints is taken up by the compliance of the the leads that are attached to components. This method of strain relief reduces the amount of damage to the joint. One problem with this solution is that the higher profile of the package creates space problems for miniaturization of the electronic package. These designs increase package size and therefore cannot provide the greater density and speed of modern technologies such as SMT. With SMT, the majority of the thermal expansion mismatch strain is taken up by the solder. Initially, this was thought to be good since the solder was "compliant" and would take up the strain without damage. However, there is still enough cyclic damage to cause fatigue failures (Pan and Winterbottom 1990, and Lau and Harkins 1988). An example of a solder joint fatigue failure in a surface mount solder joint is shown in Figure 1.

The solder alloy $60 \mathrm{Sn}-40 \mathrm{~Pb}$ is commonly used in electronic assemblies due to good wetting properties and a low melting temperature. The low melting temperature is a benefit from the point of view of producibility but could detrimentally influence lifetime reliability. At room temperature $60 \mathrm{Sn}$ $40 \mathrm{~Pb}$ is at 0.6 of its absolute melting temperature or homologous temperature, $\mathrm{T}_{\mathrm{h}}$. In severe avionics applications the temperature cycle of $-55^{\circ} \mathrm{C}$ to $125^{\circ} \mathrm{C}$ is between $0.4 \mathrm{~T}_{\mathrm{h}}$ and $0.9 \mathrm{~T}_{\mathrm{h}}$. Due to the high homologous temperatures suffered by solder alloys under these service conditions, the solder may exhibit such phenomena as viscoplasticity (i.e. creep), grain growth, hardening and/or softening due to dislocation substructure evolution, and grain boundary sliding and separation. Further, as-cast solder joints typically exhibit macro-

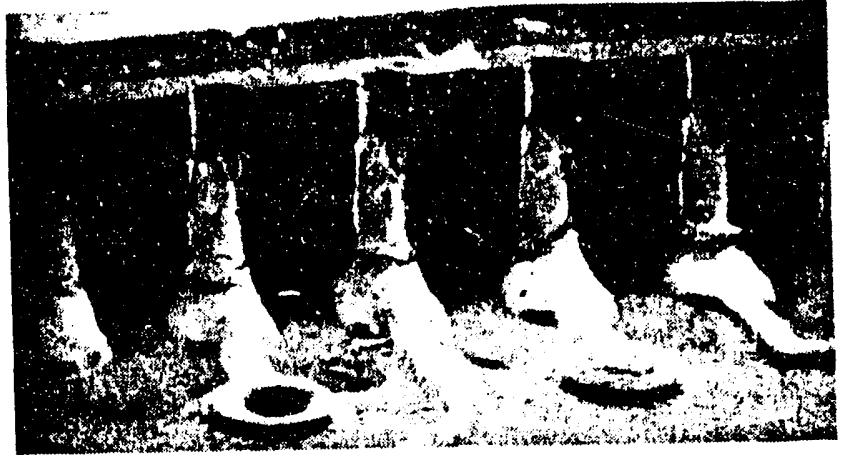

Figure 1 SEM micrograph of surface mount solder joints that failed under conditions of thermomechanical fatigue.

scale heterogeneities in the arrangement of their microstructural features. Since $60 \mathrm{Sn}-40 \mathrm{~Pb}$ is on the $\mathrm{Pb}$-rich side of the eutectic, proeutectic $\mathrm{Pb}$ dendrites are present. Dendrite formation occurs during the initial stages of solidification. The eutectic structure in the joint consists of lamellar and globular regions of $\mathrm{Pb}$-rich and $\mathrm{Sn}$-rich phases. The regions of similarly oriented lamella are separated into individual cells, or colonies. These colonies develop during solidification of the eutectic from a variety of nuclei on the solid base metal surface. The solidifying lamella grow into the molten solder and eventually intersect with other solidifying cells. The regions where the cells intersect are coarsened with respect to the lamellar structure inside the colony, and are the last regions of the joint to solidify. The starting inhomogeneous microstructure of the solder joint, combined with the cyclical high homologous temperatures and deformation mechanisms, can cause the microstructure of the joint to dramatically change. This results in a concomitant change in the mechanical properties and, therefore, the fatigue lifetime.

The reliability of solder joints under conditions of thermomechanical fatigue becomes more critical as new electronic packaging technologies evolve. In the future, larger silicon devices and the rapidly evolving multi-chip module will cause larger strains to be induced in the joints. The service environment of the solder joints is also becoming 
more severe. New power devices are running hotter. For example, electronic packages are positioned closer to the engine in automobiles for faster response and greater cost effectiveness. For increased automobile fuel efficiency, styling is more streamlined and air inlets are decreasing. This results in higher operating temperatures under the hood and greater strains in the solder joints. In avionic applications, electronic packages used for sensing, control and telemetry are exposed to severe ambient environmental temperature swings. The severity and frequency of those environmental cycles creates large cyclical strains in the solder joints. Therefore, a means of determining the reliability of solder joints is critical for improving the quality of an electronic system.

A number of methodologies have been proposed for determining reliability through lifetime prediction of solder joints under conditions of thermomechanical fatigue. A detailed summary and critical review of these methodologies is found elsewhere (Sandor 1991 and Solomon 1993). However, it is appropriate to discuss the salient points of current methodologies.

\section{CURRENT LIFETIME PREDICTION METHODLOLOGIES}

The damage to solder joints in electronic assemblies is strain-based low cycle fatigue. The most common technique to determine the lifetime of solder joints is based on the Coffin-Manson low cycle fatigue relationship [Coffin 1954, Manson 1953, Manson 1960 and Coffin 1969] which relates fatigue life, $N_{f}$, to the applied elastic and plastic strains:

$$
\Delta \gamma=\frac{\sigma_{f}^{\prime}}{E}\left(2 N_{f}\right)^{b}+\varepsilon_{f}^{\prime}\left(2 N_{f}\right)^{c}
$$

where $\mathrm{b}$ and $\mathrm{c}$ are constants (and are derived from experimental data), $\Delta \gamma$ is the average shear strain, $\sigma_{\mathrm{f}}{ }^{\prime}$ and $\varepsilon_{\mathrm{f}}$ ' are the fatigue ductility coefficients, and $\mathrm{E}$ is the elastic modulus. This methodology was developed for pressure vessel steels (304 stainless steel in particular) that underwent cyclic loading [Majumdar and Jones 1991]. For solder joints, the elastic portion of the equation is negligible and the fatigue life can be estimated as:

$$
N_{f}=\left(\frac{\Delta \gamma}{2 \varepsilon_{f}^{\prime}}\right)^{\frac{1}{c}}
$$

Life is estimated using low cycle isothermal fatigue experiments at a variety of strain ranges, drawing a straight lita on a $\log -\log$ plot of $\mathrm{N}_{\mathrm{f}}$ versus $\Delta \gamma$ and extrapolating these values to the desired strain range. The shortcoming of this methodology is that it is based solely upon the curve fitting of experimentally derived data (normally isothermal fatigue tests), the values of $c$ and $\varepsilon_{\mathrm{f}}$ ' are not fundamental by any means. Therefore, life prediction can be made only after accelerated testing of a large number of solder joints with the assumption (not always valid) that the accelerated test result mirror real use conditions.

The above formulation for the Coffin-Manson formulation has also been found to be inadequate when there is a great deal of time-dependent deformation (as occurs in solder joints) [Coffin 1971]. This inadequacy has been addressed by accounting for frequency effects in the equation. This modified formulation is written as:

$$
N_{f}=\left(\frac{\Delta \gamma}{2 \varepsilon_{f}^{\prime} v^{k-1}}\right)^{\frac{1}{c}}
$$

where $v$ is the cycling frequency and $\mathrm{k}$ is an empirical material parameter. The value of $k$ is determined by fitting the equation to the data. Again, like the modified Coffin-Manson formulation, the basis for life prediction is empirical curve fitting of existing data. Another severe limitation of this method is the fact that the formulation works only for a sinusoidal wave shape. The formulation was derived for laboratory work where sinusoidal waveshapes are easy to generate, however, the 
service loads with solder are generally not sinusoidal. Furthermore, the life plots associated with the frequency modified formulation often have a bilinear appearance. These complexities are likely due tó several factors, including microstructura! instability. No Coffin-Manson based formulation can treat this behavior explicitly.

Strain Range Partitioning is another modification of the Coffin-Manson formulation where an interactive cumulative damage rule is used to determine the fatigue life when there is a combination of PP (no creep in tension or compression), CC (creep deformation in both tension and compression), CP (creep in tension but no creep in compression) and PC (no creep in tension but creep in compression) damage, i.e.,:

$$
\frac{1}{N_{f}}=\frac{F_{p p}}{N_{p p}}+\frac{F_{c c}}{N_{c c}}+\frac{F_{c p}}{N_{c p}}+\frac{F_{p c}}{N_{p c}}
$$

where $N_{f}$ is the fatigue life, $F_{p p}$ is the fraction of the deformation which is PP, $\mathrm{N}_{\mathrm{pp}}$ is the fatigue life when pure PP deformation is used, and $F_{c c}, N_{c c}$, etc. are similarly defined. The fraction of life is determined by analyzing load versus strain hysteresis loops generated in isothermal fatigue tests. There are a number of difficulties in using strain range partitioning for solders are many. The technique does not take into account material property changes due to microstructural evolution. The SRP method requires extensive data (for curve fitting to determine $\mathrm{N}_{\mathrm{ij}}$ and $\mathrm{F}_{\mathrm{ij}}$ ). It is extremely difficult to measure the required inelastic strain components accurately in real solder joints. Finally, there is a great lack of SRP data for the shear mode of deformation and some doubts exist as to whether the technique is even applicable in shear.

Note that the Coffin-Manson formulations described above do not take solder alloy, processing history or microstructure into account. The Coffin-Manson formulation assumes that the material is monolithic and is time/history independent.

Fracture Mechanics lifetime approaches have also been applied to solder joints [Pao and Pan 1990, Wong et al. 1988, Yamada 1988 and 1989] most notably the $\mathrm{J}$ and $\mathrm{C}^{*}$ approaches [Solomon et al. 1990]. The fracture mechanics approach assumes failure occurs when a crack, that initiates on the first cycle, propagates through the joint. The most serious limitation to the fracture mechanics approach is the ductility of the solder necessitates the use of a fairly large testing specimen that may not have a structure or geometry similar to that found in the small solder joints in electronic assemblies. A further limitation is that the microstructure cannot be implicitly included in the model.

A reliability tool based on Figures of Merit has been developed to estimate fatigue life of solder joints [Clech et al. 1989]. In the Figures of Merit approach, experimental data (such as isothermal fatigue lifetimes and lead compliances) are combined to compare one joint design with another using a series of formulas. This technique is accurate when there is sufficient field data to incorporate into the model. The technique is especially useful for considering small variations in design when the thermal environment is not severe. The methodology breaks down in severe thermal/mechanical environments and for designs where no empirical data exists.

The consistent problem with the currently available solder joint lifetime prediction mezhodologies is that they are empirically based and therefore specific to the conditions of the test. The models use isothermal fatigue tests where real electronic assemblies undergo thermomechanical fatigue. The solder alloy, its processing history and microstructure are typically ignored and the joint is treated as an isotropic, unchangirig, homogeneous material. The models are only directly applicable to systems that see the same conditions as the empirically derived data. The empirical data is not fundarnental and cannot be generally applied. We present a new approach that integrates experimental results and computational techniques to predict fatigue life. 


\section{METHODOLOGY}

We present a proposed solder joint fatigue life prediction methodology that uses simplified experimental fatigue tests as the fundamental input parameters for a computational model. The methodology is broken out into four interrelated stages. The first stage involves correlating the manufacturing and processing parameters in order to predict the initial geometry of the joint. The second stage involves a series of experiments that serve to characterize the solder microstructure and thereby provide input for constitutive relations for stage three. The third stage is a computer modeling and simulation effort that uses the predicted joint geometry and experimentally derived microstructural data as initial conditions. The last stage consists of experimental tests to confirm the results of the computer model.

\section{EXPERIMENTAL TECHNIQUES}

In the process of formulating a solder joint lifetime prediction capability a number of experimental and computational techniques must be developed. The project involves thermomechanical fatigue tests on solder joints to determine the microstructure, and hence the properties of the joint, and computational techniques to predict reliability based upon the experimental results. The following is a summary of these techniques. The solder alloy used in these tests is the near eutectic $60 \mathrm{Sn}-40 \mathrm{~Pb}$ solder on copper substrates.

\section{Solder Joint Geometry Computational Simulation}

One of the difficulties in computational thermomechanical simulation of solder interconnects is that the joint geometry is not known prior to, and in fact forms during, the soldering process. The solder joint shape is a function many variables including geometry of the parts being soldered, inherent properties of the materials being soldered, surface roughness, cleanliness, and a variety of other process variables. Computational simulation of interconnects requires that the joint geometry be specified. There are several methodologies used to specify the geometry of the joint with the first being simply to assume the geometry. Second, the geometry can be defined by physical examination of cross-sections of actual solder joints. Third, the external geometry can be obtained from advanced inspection techniques (Read, 1991; Paydar, et al., 1991). Finally, methodologies are being developed to predict the geometry of the joint. Current predictive methodologies are either analytically based (Heinrich, et al., 1990a; Heinrich, et al., 1990b; Liedtke, et al., 1991; Heinrich, et al. 1992; Patra and Lee, 1990) or numerically based (Brakke,1991, 1992; Racz, et al., 1993; Racz and Szekely, 1993; Weatherby, et al., 1989). For production simulation of solder interconnects, the numerically based methodology offers significant advantages, however, the meshing required for joint geometry computational simulation is not adequate for finite element thermomechanical simulations. To couple joint geometry models with thermomechanical simulation models, the intent is to leverag 2 off of current ongoing research and development of automatic 3D meshing capabilities.

\section{Computational Simulation Techniques}

The lifetime of the solder joints under conditions of thermomechanical fatigue will be modeled using finite element methods. Microstructural state variables suggested by the in situ thermomechanical fatigue tests are incorporated into a temperature-dependent, isotropic, elastic-viscoplastic constitutive framework. A time integration algorithm for the complete constitutive model is used in a three-dimensional finite element codes. To confirm the correctness of the model, boundary value problems that correspond to experimental geometries and conditions are studied. 


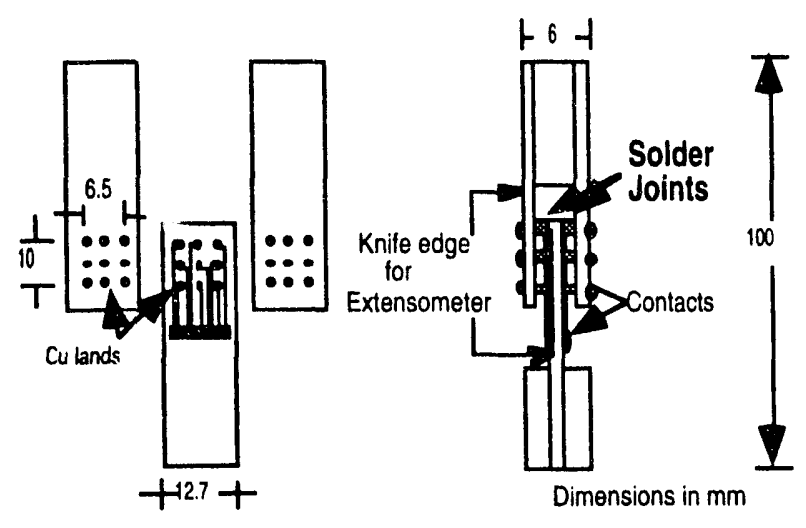

Figure 2 Schematic drawing of the specimen used for thermomechanical fatigue testing of solder joints.

\section{Thermomechanical Fatigue Tests}

To date the thermomechanical fatigue tests have been performed in a simple shear orientation to provide information on microstructural evolution, and as a check for the modeling results. This procedure is described in greater depth elsewhere [Frear 1989]. A brief summary of the test method is given below.

The specimen used to test solder joints is shown in the schematic drawing in Figure 2. The specimen consists of 18 electrically isolated solder joints that, when the specimen is gripped on the ends, deform in simple shear. The joints have a simple truncated spherical geometry that is simple to model.Strain is imposed upon the solder joints by a servohydraulic load frame operated under strain control. Thermal fluctuations are induced by a chamber that fits around the specimen in the load frame. Compressed air is heated and cooled by a commercial heating and cooling system and circulates around the specimen. The strain and temperature are digitally controlled by a computer. The temperature extremes are $-55^{\circ}$ to $125^{\circ} \mathrm{C}$ at $10 \%$ shear strain. The thermal cycle consists of a ramp in strain and temperature to the elevated temperature extreme and hold period, a ramp down, and another hold at the low temperature extreme.

Failures are monitored electrically using an event detector. The event detector measures spikes in resistance of greater than $500 \Omega$ for periods of time less than $1 \mu \mathrm{s}$. Event detector data along with load, temperature, and strain are collected and stored digitally.

To examine the microstructure of the solder joints after testing, the samples were mounted and metallographically sectioned and polished to reveal the solder microstructure.

\section{In Situ SEM Thermomechanical Fatigue Tests}

Due to the fact that solders in electronic systems are used at a high fraction of their homologous temperature, the microstructure is expected to evolve during the test. To date, the microstructural characterization methods involve sectioning samples for observation after a given number of cycles. This is a time consuming process and results in only a snapshot of the evolution of the microstructure. In order to develop a good model the microstructure must be quantified throughout the deformation process. This can be performed using an in situ scanning electron microscope (SEM) and subsequent image analysis.

In order to examine real time microstructural evolution of solder during fatigue an in situ SEM with a deformation stage has been built. A schematic illustration of the system is shown in Figure 3 and a photograph of the system and chamber is shown in Figure 4. The SEM is equipped with a servohydraulic loadframe (inside the vacuum chamber) that can impose strain on a sample at a constant strain rate while the SEM is collecting images. In order to perform thermomechanical tests on the solder cyclically heated and cooled air is circulated through a closed loop in the chamber to heat and cool the grips, and therefore the sample. The net result is a real time ob:,ervation of the thermomechanical deformation process of the solder microstructure. The SEM can be operated in secondary or backscatter mode. For $\mathrm{Pb}-\mathrm{Sn}$ solder the difference in atomic weight is great so operating in backscatter mode clearly reveals the structure of the solder. The SEM is a digital storage 


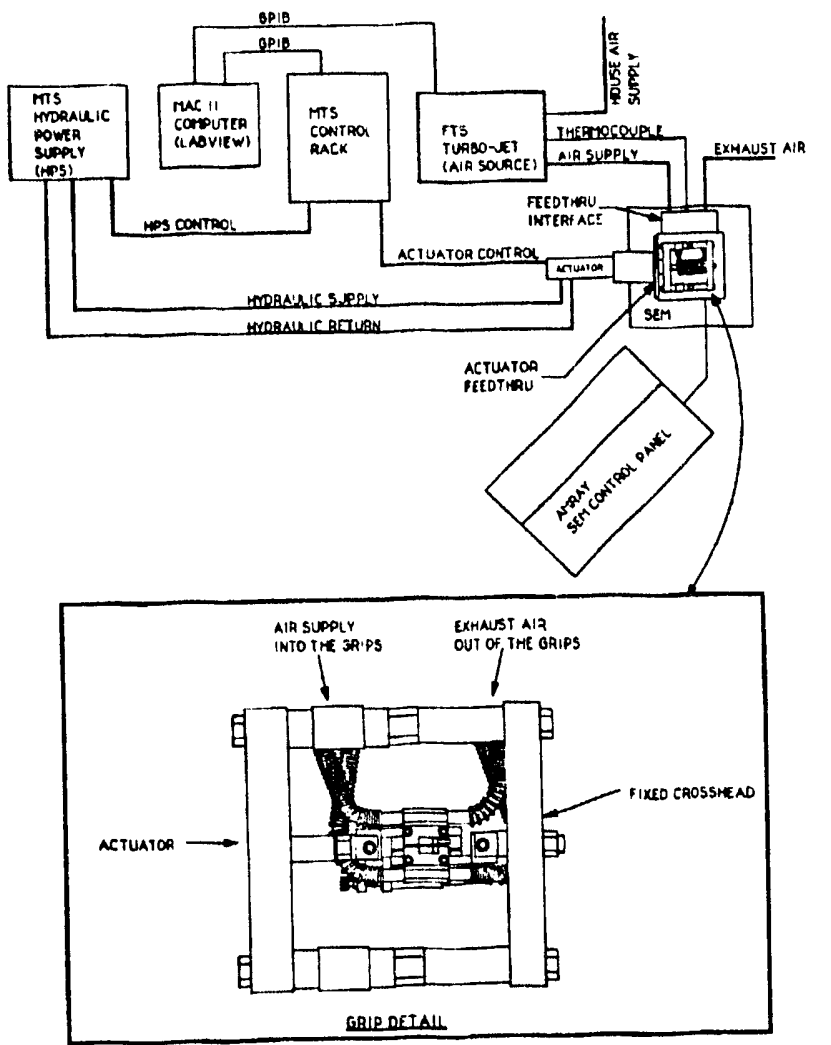

Figure 3 Schematic drawing of the in situ SEM used to perform thermomechanical fatigue tests.

microscope so that undistorted images can be taken of the solder microstructure during deformation.

The microstructural development will be quantified by digitizing the analog images from the SEM and capturing them on a hard disk for computer analysis. Any heterogeneities in strain concentrations or the microstructure can then be quantified. The digitized microstructure can then be used for the modelling effort.

The results of the in situ deformation studies also provides the basis for the determination of microstructural state variables needed for the finite element simulations. The resultant microstructures can be assigned mechanical properties based upon a number of measurable variables (cell size, grain size, phase size and lamellar spacing).

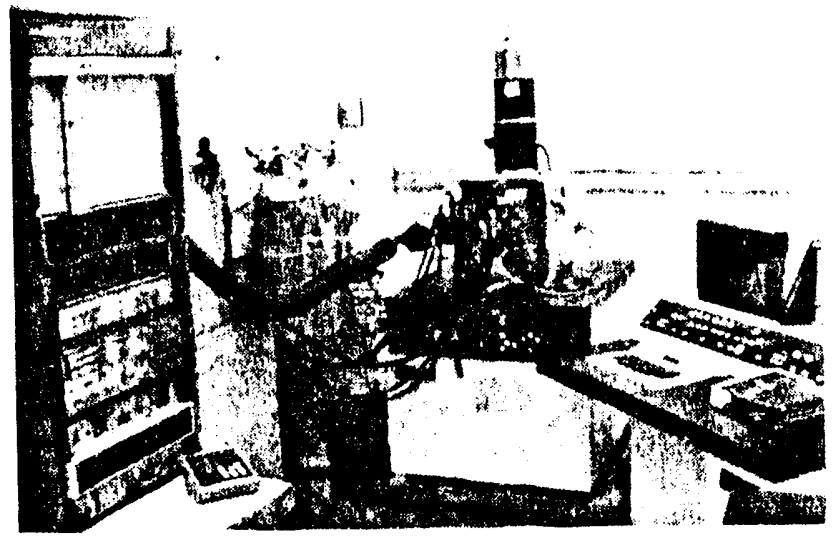

Figure 4 Photograph of the in situ SEM system.

\section{CURRENT STATUS}

Thermomechanical fatigue tests were performed on $60 \mathrm{Sn}-40 \mathrm{~Pb}$ solder joints at $10 \%$ shear strain and the resultant microstructure characterized. Figure 5 shows the inhomogeneous microstructural evolution of a solder joint that occurs during thermomechanical fatigue. In the as-solidified state (Figure 5A), the solder consists of fine twophase lamellar colonies that are separated by slightly coarsened eutectic boundaries. Figure 5B shows a heterogeneous coarsened band that develops during thermomechanical fatigue cycling. The response to further imposed strain is dependant upon the state of evolution in the microstructure. Upon further cycling cracks form in the coarsened band and the solder joint fails as shown in Figure 5C.

Quantification of the microstructural evolution will be performed using the in situ thermomechanical fatigue scanning electron microscope. An example of the results from this experiment is shown in Figure 6. Figure 6A is at the low temperature portion of the cycle $?$ nd Figure $6 \mathrm{~B}$ is at the high temperature portion after imposing $10 \%$ shear strain. The deformation concentrates at the cell boundaries where the eutectic cells slide relative to one another. These boundaries are marked by arrows in the figure. Accommodation of deformation by sliding at cell boundaries has been observed by Lee and Stone [1990]. The 

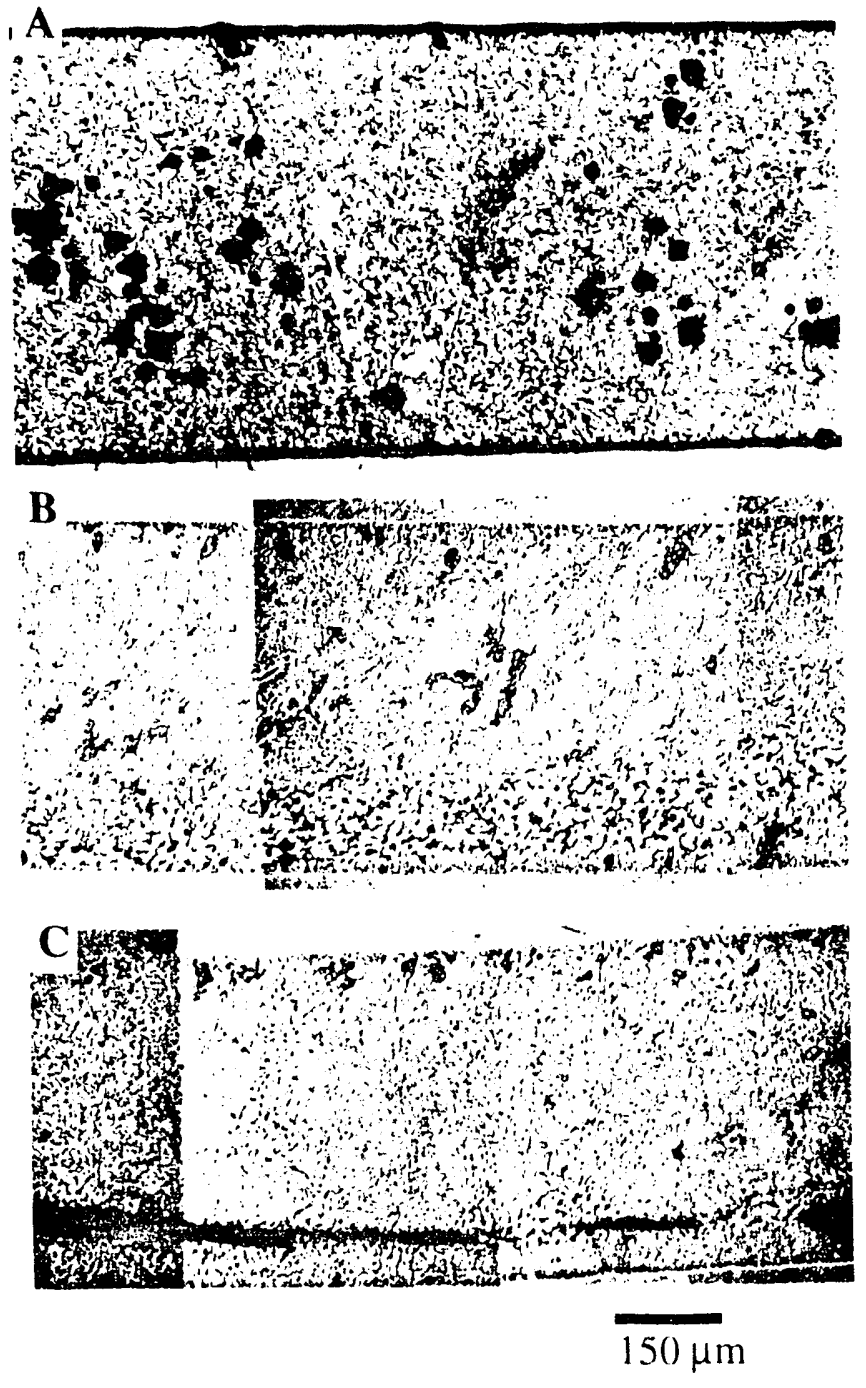

Figure 5 Optical micrographs that show the evolu tion of $60 \mathrm{Sn}-4(\mathrm{~Pb}$ microstructure during thermomechanical fatigue: A) as-solidified, B) after 100 cycles, C) at failure.

microstructural evolution will be digitized so that the changes can be incorporated into a computer model. Constitutive relations, based upon the microstructure, will be constructed that incorporate the time dependent nature of the solder.

In order to predict the lifetime of the solder joints any model must include this microstructural evolution. The computer model will incorporate the constitutive behavior of the solder and its microstructural evolution. The model will also incorporate the geometry of the solder joint. The
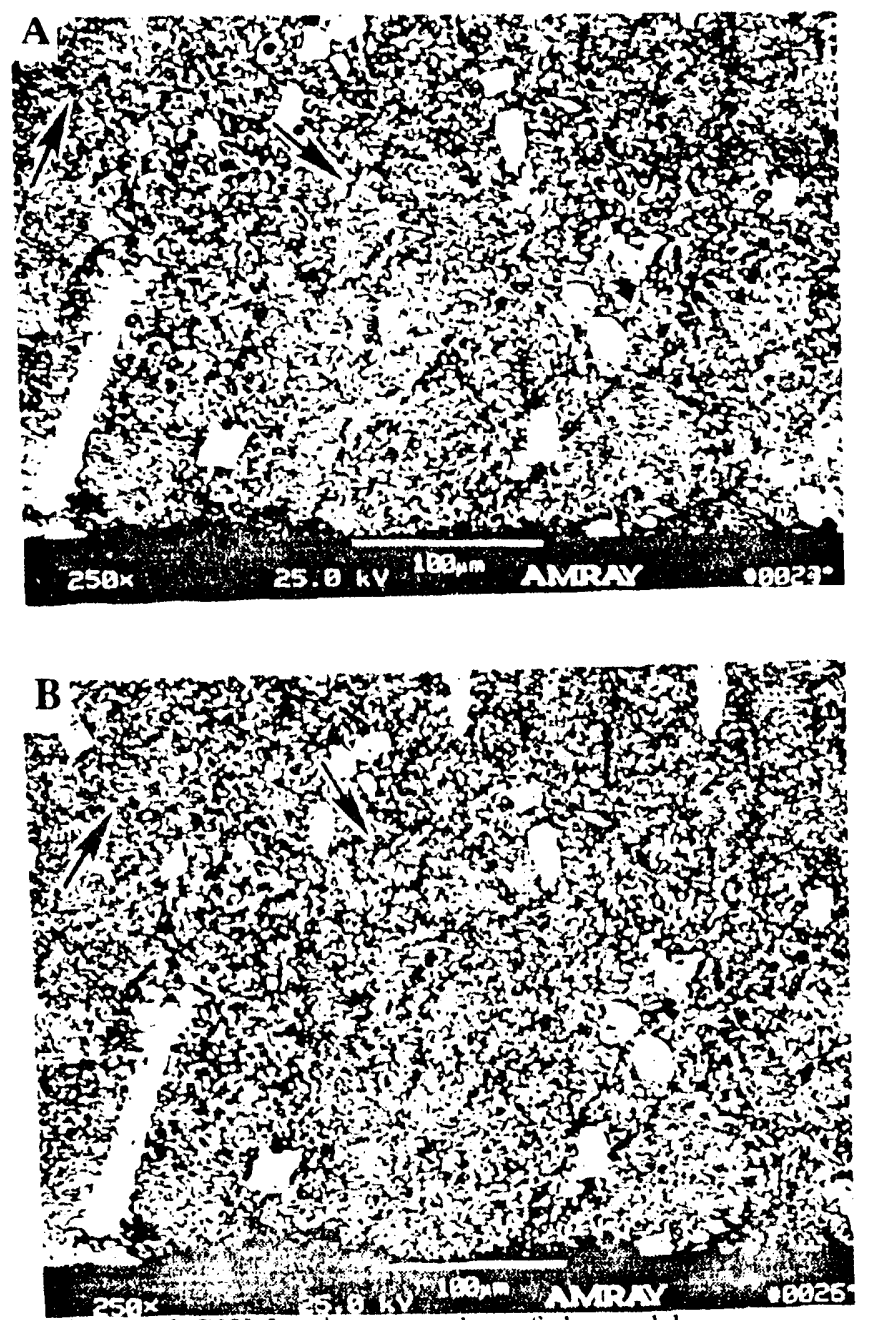

Figure 6 SEM micrographs of the solder microstructure taken in the in situ scanning electron microscope. A) low temperature portion of the thermal cycle, B) high temperature portion of the cycle at $10 \%$ shear strain. Arrows mark changes in the microstructure.

numerically based joint geometry simulation codes SURFACE EVOLVER (Brakke,1991, 1992) and SANCHO (Weatherby, et. al., 1989) are currently being evaluated for applicability to prediction of solder joint shapes.

The impact of the experimental results on the solder joint lifetime work is threefold: first, microstructural characterization of solder, both before and after cyclic loading, will be used to mo- 
tivate the choice of state variables in the constitutive model; second, parameter values for the material model will be estimated from both standard and nonstandard tests; and third, the accuracy and value of the lifetime predictions will be assessed by comparison to actual fatigue tests. A preliminary model has been formulated and implemented in the three-dimensional finite element code JAC3D (Biffle 1990), in which the eutectic solder is treated as a mixture of tin-rich and leadrich phases, and a characteristic phase-region size (i.e. coarseness) is represented by a single scalar variable. This model is intended to replicate some aspects of the cyclic behavior of $\mathrm{Sn}-\mathrm{Pb}$ eutectic solder under conditions in which coarsening of the microstructure is to be expected. Initial computational results seem to suggest that models of this kind are capable of representing the localization of deformation in coarsened bands that is often observed in cycled solder joints.

Once confidence in the finite element simulations has been gained, the eventual goal will be to formulate a global failure criterion for general solder joints that can be evaluated based on the results of a simulation. In particular, what is sought is a small set of parameters that are functions of the state of the material throughout the solder joint, and which can be evaluated by post-processing of the simulation results. Since practical considerations preclude the simulation of large numbers of loading cycles, the global failure parameters must be extrapolated based on their behavior in only a few cycles. Lifetime predictions may then be made based on the satisfaction of the extrapolated failure criterion. This approach is necessarily very approximate. However, it seems probable that such an approach will be more accurate in predicting solder joint life than are current techniques, which are based on, e.g., gross measures of accumulated plastic strain.

\section{SUMMARY}

In this paper we have outlined a new methodology that is being developed to model the thermomechanical fatigue process in solder joints in order to make lifetime (reliability) predictions. The cur- rently available methods are limited because they are based on empiricism and ignore the effects of the microstructure thereby perhaps overestimating fatigue life.

Studies thus far have shown that the near eutectic $\mathrm{Sn}-\mathrm{Pb}$ solder microstructure, that is typically used for electronic applications, undergoes a heterogeneous coarsening process that concentrates the strain into a small region of the joint. Failure eventually occurs within the coarsened region. The model will incorporate this evolution, and features of the microstructure. The entire effort is divided into three stages. The first involves incorporating heat transfer, joint pad geometry, and molten solder surface energies to predict both the as-solidified geometry and microstructure and automatically meshing this geometry for subsequent finite element analysis. The second stage involves the use of an in situ scanning electron microscope that has a deformation stage in order to quantify the evolution of the solder microstructure during thermomechanical fatigue and thereby provide input to the constitutive relations. The third stage involves a finite element modeling effort using these constitutive relations to predict the lifetime and reliability of solder joints under conditions of thermomechanical fatigue.

\section{ACKNOWLEDGMENTS}

This work performed at Sandia National Laboratories supported by the U.S. Department of Energy under contract DE-AC04-76DP00789.

\section{REFERENCES}

Biffle,J.H., "JAC3D - A Three-Dimensional Finite Element Computer Program for the Nonlinear Quasi-Static Response of Solids with the Conjugate Gradient Method", Sandia Naiional Laboratories report SAND87-1305, Albuquerque, NM, Sept. 1990.

Blacker,T.D., "FASTQ Users Manual Version 1.2," SAND88-1326, Sandia National Laboratories, Albuquerque,NM.1988.

Blacker,T.D., Stephenson,M.B., "PAVING: A New Approach to Automated Quadrilateral
Frear, Rashid and Burchett 
Mesh Generation," International Journal for Numerical Methods in Engineering,Vol.32,81 1-847,1991.

Brakke, K.A., 'The Surface Evolver," Exp. Math., in press, 1992.

Brakke, K.A., Surface Evolver Manual, version 1.65, Research Report GCG 31, The Geometry Center, 1300 S. Second St., Minneapolis, MN 55454, 1991.

Burchett,S.N.,"Stress Analysis of a Leadless Chip Carrier Soldered to a Ceramic Substrate", ASME Winter Annual Meeting, Dec. 16,1991,Atlanta,Ga.(1991) 91-WA-EEP- 1. Charles,H.K.,Jr and Clatterbaugh, G.V.,"Solder Joint Reliability -- Design Implications from Finite Element Modeling and Experimental Testing,"ASME Journal Electronic Packaging, Vol. 112,No.2 (1990) pp. 135-146.

Clech, J-P., Englelmaier, W., Kotlowicz, R. W. and Augis, J. A., SMART Conf. V, New Orleans, LA (1989).

Coffin, L. F., J. Mater., vol. 6 (1971) pp. 388-402.

Coffin,L.F.Jr., Trans. ASME V76, 1954,pp.931950.

Coffin,L.F.Jr.,in Fracture 1969, Chapman and Hall, London 1969.

Frear, D. R., IEEE Comp. Hybrids. Manufact. Tech., CHMT-12 (1989) pp. 492-501.

Heinrich,S.M., Elkouh,A.F., Nigro,N.J., and Lee,P.P., 1990a, "Solder Joint Formation in Surface Mount Technology -- Part I:Analysis,"ASME J. Electronic Packaging, Vol. 112, No.3 (1990a) pp.210-218.

Heinrich,S.M., Nigro,N.J., Elkough,A.F. and Lee,P.S., "Solder Joint Formation in Surface Mount Technology -- Part II:Design,"ASME J. Electronic Packaging, Vol. 112, No. 3 (1990b) p.219-222.

Heinrich,S.M.,Liedtke,P.E., Nigro,N.J., Elkouh,A.F., Lee,P.S.,"Effect of Chip and Pad Geometry on Solder Joint Formation in SMT," ASME/JSME Joint Conference April, 1 992,San Jose, CA.

Jones,R.E., "QMESH:A Self-Organizing Mesh Generation Program," SLA-73-1088, Sandia National Laboratories Albuquerque,NM,1974.

Lau, J. H. and Harkins, G., "Thermal-Stress Anal- ysis of SOIC Packages and Interconnections", Proc. IEEE 38th ECC Conf., 38, (1988) p. 2331.

Lau.J.H., and Rice,D.W., "Effects of Interconnection Geometry on Mechanical Responses of Surface Mount Component," PROC.,2nd IEEE International Electronic Manufacturing Technology Symposium, San Francisco, CA (1986) pp.205-217.

Lee, S. M., Stone, D. S., Proc. 40th IEEE ECTC Conf., Las Vegas, NV (1990) p. 491.

Liedtke,P.E., Heinrich,S.M., Elkouh,A.F., Nigro,N.J. Lee,P.S.,"Prediction of Wave-Soldered Fillet Geometry in SMT Applications," ASME Winter Annual Meeting, Dec 16,1991, (1991) Atlanta GA.

Majumdar, S. and Jones, W. B., "How Well Can We Predict the Lifetime of a Well-Characterized Material", Solder Mecharics: A State of the Art Assessment, D. R. Frear, W. B. Jones and K. R. Kinsman, eds., TMS publications, (1991).

Manson,S.S.,"Behavior of Materials Under Conditions of Thermal Stress", Heat Transfer Symposium, Univ of Michigan, June 2728,1952, Univ. of Mich.Press;also NACA TN2933, July 1953.

Manson,S.S.,Mech. Des. V32(14), 1960, pp.139144.

Pan, T.-Y. and Winterbottom, W. L., "Thermal Cycling Induced Plastic Deformation in Solder Joints", Proc. ASME Winter Annual Meeting (1990).

Pao, Y. H., Pan, T. Y., Trans. ASME, J. Electron. Pack., Trans., vol. 112 (1990) pp. 154-161.

Patra,S.K., Lee,Y.C., "Quasi-static Modeling of Self-Alignment Mechanism in Flip-Chip Soldering. Part I:Single Solder Joint," ASME Winter Annual Meeting, Nov. 25-30 (1990) Dallas, TX, 90-WA/EEP-37.

Paydar, N., Hasan,A.U.,Tong,Y., "Thermal Stress Analysis of an Solder Joint Using a CreepPlasticity Model," Electrecon'91 Proceedings, Oct 22-23,1991 Indianapolis, IN (1991) pp. 113- 125.

Racz, L.M., and Szekely, J., "Determination of Equilibrium Shapes and Optimal Volume of Solder Droplets in the Assembly of Surface 
Mounted Integrated Circuits," in press, Trans., ISIJ International, 1993.

Racz, L.M., Szekely, J., and Brakke, K.A., "A General Statement of the Problem and Description of a Proposed Method of Calculation for Some Meniscus Problems in Materials Processing," in press, Trans., ISIJ International, 1993.

Read,D.T. and Bayba,A.",Extraction of Solder Joint Perimeters from Laminography Images and Application to Life Prediction," ASME Winter Annual Meeting, Dec 1-6,1991, Atlanta, Ga. (1991) 91-Wa-EEP-17.

Solomon, H. D., Brozowski, V., Thompson, D. G., Proc. 40th Electron. Comp. and Tech, Conf., Las Vegas, NV (1990) pp. 351-359.

Weatherby,J.R., Krieg,R.D., Stone,C.M., "Incorporation of Surface Tension into the Structural Finite Element Code SANCHO," SAND89. 0509, Sandia National Laboratories, Albuquerque, NM., March,1989.

Wong, B, Helling, D. E., Clark, R. W., IEEE Trans, CHMT, vol. 11 (1988) pp. 284-290.

Yamada, S. E., Eng. Fract. Mech, vol. 27 (1987) pp. 315-328.

Yamada, S. E., Eng. Fract. Mech, vol. 29 (1988) pp. 673-682. 


\section{DISCLAIMER}

This report was prepared as an ascount of wort sponsored by an agency of the United States Government. Neither the United States Government nor any agency thereof, nor any of their employees, makes any wnrmaty, express or inolied, or assumes any legal liability or responsibility for the accuracy, completeness, or usefulness of any information, apparatus, product, or process disclosed, or represents that its use would not infringe privately owned rights. Reference berein to any specific commercial product, process, or service by trade name, trademark, manufacturer. or otherwise does not necessarily constitute or imply its endorsement, recommendation, or favoring by the United States Government or any agency thereof. The views and opinions of authors expressed herein do not necassarily state or reflect those of the United States Governmeat or any ageacy thereof. 

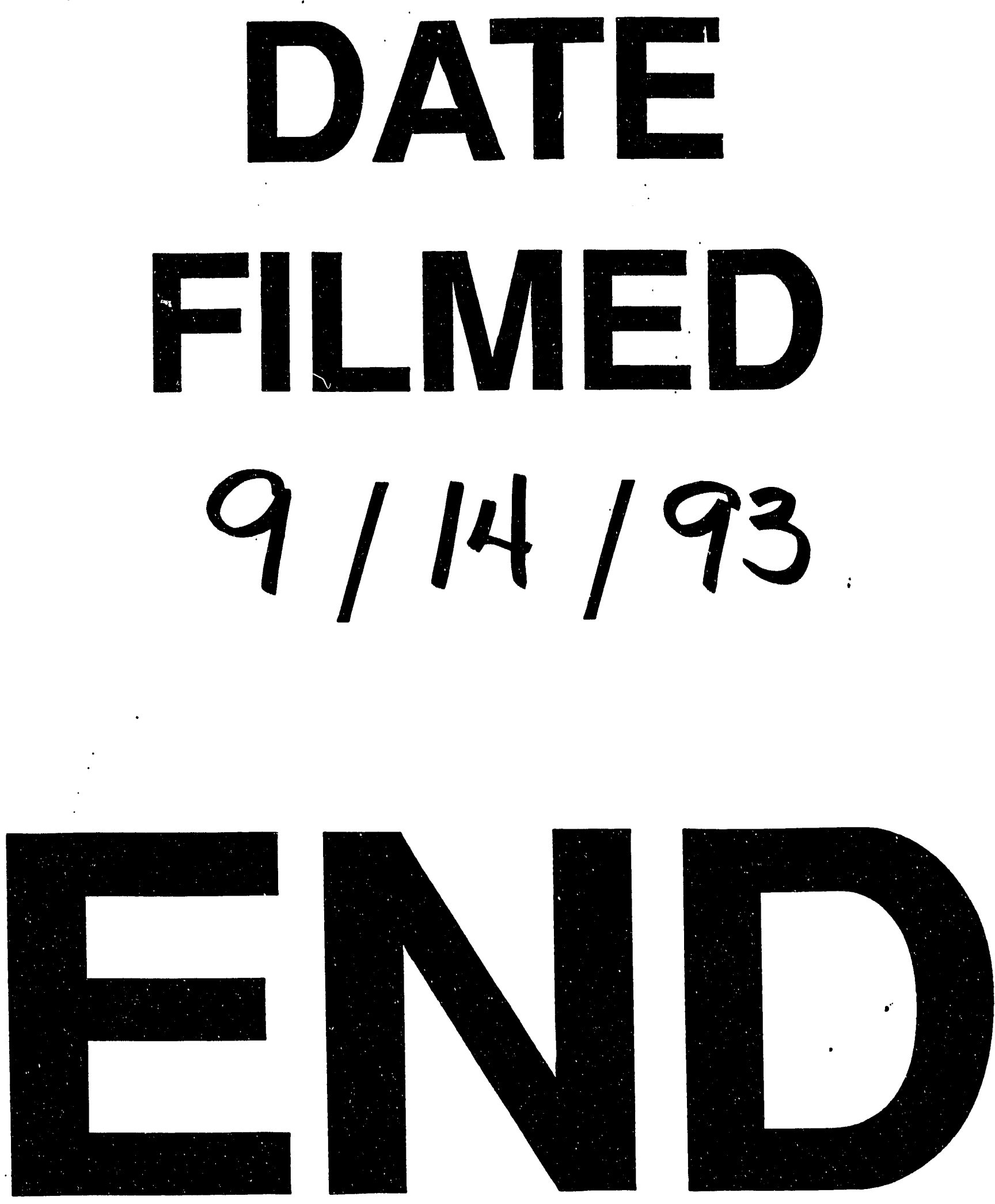
